\title{
Stimulus familiarization (n) in nonverbal selective learning'
}

CLYDE E, NOBLE, JAMES P. ALLISON AND THOMAS A. JONES UNIVERSITY OF GEORGIA AND UNIVERSITY OF MONTANA

One-hundred sixty Ss practiced 10-choice 4-unit tasks on the Selective Mathometer for 40 noncorrection trials under one of 8 different experimental conditions. The stimuli were paralogs of low meaningfulness and familiarity on Noble's $m$ and $f$ scales, presented in a paired-associate fashion. The 8 matched groups of $20 \mathrm{Ss}$ each were formed by 6 combinations of 3 levels of relevant stimulus familiarization and 2 kinds of criterion-task stimulus treatment plus 2 high-frequency irrelevant stimulus familiarization and articulation control conditions. There were large, significant practice effects but no main effects or interactions due to the other experimental conditions. The null results pose difficulties for theories of stimulus predifferentiation.

It is known that experimentally-controlled familiarization (n) increases familiarity, strengthens free recall, and facilitates serial and paired-associate verballearning proficiency, the amount and direction of the effects depending upon frequency, temporal, and articulation factors (Baker \& Noble, 1965; Noble, 1963). Comparable experiments for selective-learning tasks have not been performed, although a number of studies of "verbal pretraining"' and "stimulus predifferentiation" share common features with verbal familiarization research. The pertinent literature has recently been reviewed by Ellis (1965), Hall (1966), and Noble (1966). In this "transition" experiment a variant presentation method is used. It requires $S$ to attend carefully to successive stimuli in order to select the correct reaction keys with promptness and accuracy. Although the pretraining is eminently verbal, $S$ 's verbalizations do not indicate the correct manual reaction to be associated later with each stimulus; articulation during familiarization is logically unrelated to responses demanded by the criterion task in the transfer phase. On the other hand, stimulus pronunciation during transfer is not incompatible with key pressing, so the problem of verbalizations interfering with criterion responses is avoided. According to predifferentiation theorists, stimuli of low meaningfulness $(m)$ and familiarity ( $\underline{f})$ are initially not very distinctive to control Ss. Therefore, if the familiarization treatment is relevant (assuming task comparability), then experimental Ss should profit from increasing amounts of such pretraining, while Ss who pronounce the stimulus term during the transfer phase should outperform Ss who do not. Negative results would imply additional restrictions on the range of application of predifferentiation theories.

Method

The Ss were 160 undergraduates at the Universities of Montana and Georgia. There were 77 men and 83 women, whose ages ranged from 15 to $58 \mathrm{yr}$. (mean $=$ $22.7 \mathrm{yr}$.). All were naive to verbal and selective learning. The apparatus used for both matching and criterion tasks was the Selective Mathometer (MK II), described elsewhere in detail (Noble, 1966; Noble, Fuchs, \& Thompson, 1963). An S's problem is to discover which one of 19 pushbuttons is to be selected in response to each slide presented on a projection screen. The reinforcing stimulus for correct responses $\left(R_{+}\right)$is the onset of a 3-w green light centered above S's keyboard. All events are recorded by counters and polygraph. The time constants were: stimulus duration $=2 \mathrm{sec}$., interstimulus interval $=2$ sec., intertrial interval $=8$ sec., reward delay $=0$ sec., reward duration $=3 / 4 \mathrm{sec}$. For the $6-$ choice 6-unit matching task 6 keys were unmasked (no. $3,5,9,11,15,17$ ), and all were relevant. For the 10choice 4-unit criterion task 10 keys were available (no. $1,3,5,7,9,11,13,15,17,19$ ), but only 4 were relevant (no. $1,7,13,19$ ).

Stimuli for the matching task were 6 distinctive electrical circuit symbols; stimuli for the criterion task were 4 disyllabic paralogs of low meaningfulness (mean $\underline{m}=1.26$ ) and low familiarity (mean $\underline{f}=0.28$ ) on the $\underline{m}$ and $\underline{f}$ scales (cf., Noble, 1963). All ss practiced by the E-paced noncorrection procedure, receiving 10 trials of an invariant $S-R$ sequence on the matching task and 40 trials of a variant S-R sequence in 8 different orders on the criterion task (or 5 successive perfect trials). Stimuli for the familiarization task were prepared in 2 lists of 8 paralogs each (mean $\underline{m}=$ 1.28; mean $\underline{f}=0.33$ ) and presented by a Stoelting memory drum at a 2-sec. rate in 6 different orders. The Ss were instructed to pronounce each paralog aloud as it appeared and to maintain consistency of pronunciation.

The experiment was divided into 3 phases: matching task, familiarization task, criterion task. After the first hase, $20 \mathrm{Ss}$ of comparable ability were assigned to each of 8 treatment conditions to be administered in the second and third phases. There were three levels of stimulus frequency (n) during the familiarization phase, denoted as $0-F, 20-F$, and 40-F. Each of these conditions was followed by one of two kinds of criteriontask stimulus treatment, denoted as F-P (pronunciation) and F-NP (no pronunciation). The above 6 combinations gave 4 groups of $\mathrm{Ss}$ receiving relevant familiarization experience (20-F-P, 20-F-NP, 40-F-P, 40-F-NP) and 2 groups with none $(0-F-P, 0-F-N P)$. Two additional control groups received high-frequency $(\underline{n}=40)$ irrelevant familiarization experience in the second phase and one of the two articulation treatments in the third phase; they are denoted as 40-I-P and 40-I-NP. Four 


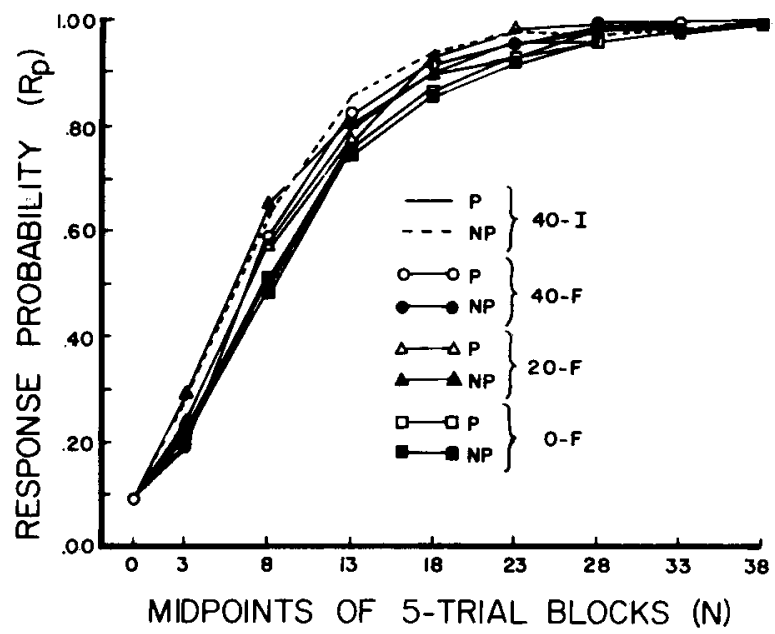

Fig. 1. $R_{p}$ curves for the 8 groups as a function of $\mathbf{N}$. Each curve contains $20 \mathrm{Ss}$.

of the 8 paralogs presented during the second phase were critical items for $S s$ in the 20-F and 40-F groups; the remaining 4 stimuli were fillers. No Ss in the $0-F$ groups received familiarization; Ss in the 40-I groups were familiarized with 8 stimuli not encountered in the third phase. All details of programming the stimulus and response permutations during the third phase were based on a previous experiment (Farese \& Noble, 1960). Results

Acquisition curves for all 8 groups on the criterion task are shown in Fig. 1 plotted in terms of response probability $\left(R_{p}\right)$, or relative frequency of $R_{+}$, as a function of successive 5-trial blocks (N). Each curve has the familiar skewed, sigmoidal form characteristic of selective-learning tasks (Noble, 1966), and is approaching mastery by the sixth block of practice. A 6 by 3 by 2 mixed-factorial Trials by Familiarization by Pronunciation analysis-of-variance test was performed on the $\mathrm{R}+$ data of the relevant-familiarization experimental and control groups over Trials 1-30. The Trials main effect was significant $(F=801.06$; $d f=5 / 570$; $\mathrm{p}<.001)$, the Trials by Familiarization interaction was marginal $(F=1.78 ; \mathrm{df}=10 / 570 ; .05<\mathrm{p}<.10)$, but no other main effects or interactions were notable $(p>.20)$. Similar statistical tests involving comparisons of the two irrelevant-familiarization groups with selected experimental and control groups failed to reveal any significant variances apart from associative changes. Discussion

The evidence is clear that, except for the usual large, significant practice effects in selective-learning tasks of this type (Noble, 1966), no important main effects or interactions due to the other experimental conditions were found. There was a slight tendency for Familiarization to interact with Trials in Fig. 1, but the variance ratio did not reach the conventional level of statistical acceptability. We conclude that neither (1) stimulus familiarization prior to learning nor (2) pronouncing the stimuli during learning produced any theoretically interesting influence on Mathometer performance. Perhaps the null results are attributable to the verbal stimuli being distinctive enough originally to permit attaching manual responses in an optimal manner without assistance from familiarization or pronunciation. Or, there may be "verbal-motor" differences which render the criterion tasks incomparable and the analogy strained. There is another possibility. Since the familiarization procedures, temporal constants, and articulation factors are so similar in the present experiment and in paired-associate verbal studies, the critical variable could be the nature of the criterion responses and/or the reinforcing events. These are markedly different in verbal-learning and selective-learning situations; indeed the difference may preclude such gap-bridging attempts as the present study. At any rate, our negative findings appear to further delimit the kinds of task to which current theories of stimulus predifferentiation may be applied.

\section{References}

Baker, B. L., \& Noble, C. E. Effects of time factors in pairedassociate verbal learning. J. verbal Learn. verbal Behav., 1965 4, 437-445.

Ellis, H. C. The transfer of learning. New York: Macmillan, 1965.

Farese, F. J., \& Noble, C. E. Trial-and-error vs. mixed-selective learning in man. Percept. mot. Skills, 1960, 10, 115-122.

Hall, J. F. The psychology of learning. Philadelphia: Lippincott, 1966.

Noble, C. E. Meaningfulness and familiarity. In C. N. Cofer \& B. S. Musgrave (Eds.), Verbal behavior and learning: problems and processes. New York: McGraw-Hill, 1963. Pp. 76-119.

Noble, C. E. Selective learning. In E. A. Bilodeau (Ed.), Acquisi tion of skill. New York: Academic Press, 1966. Pp. 47-97.

Noble, C. E., Fuchs, J. E., \& Thompson, J. D. A new automatic circuit for the Selective Mathometer (MK II). J. Psychol., 1963 $55,241-257$.

\section{Note}

1. This report was prepared by the senior author with support from the Office of Naval Research under Contract Nonr-3677(02) and from the Air Force Office of Scientific Research under AFOSR Grant 1099-66. Reproduction in whole or in part is permitted for any purpose of the United States Government. The study is based on a 1965 master's thesis performed by J.P. A. under the guidance of C. E. N. at the University of Montana, and on Supplementary data collected by T. A. J. and C. E. N. at the University of Georgia. Assisting in data analysis were Carl L. Clay, Joan E. Eldodt, Helen R. Jones, Ella M. Rowe, and C. Ronald Saunders. 